\title{
Configurações
}

Revista de sociologia

\section{O Estatuto Profissional e a Natureza da Figura do Agente de Execução}

The Professional Status and Nature of the Figure of the Executive Requester Le statut professionnel et la nature de la figure d'huissier de justice

\section{Luís Neves e Sandra Sousa}

\section{OpenEdition}

\section{Journals}

\section{Edição electrónica}

URL: http://journals.openedition.org/configuracoes/4238

DOI: $10.4000 /$ configuracoes. 4238

ISSN: $2182-7419$

\section{Editora}

Centro de Investigação em Ciências Sociais

Edição impressa

Paginação: 109-124

ISSN: 1646-5075

\section{Refêrencia eletrónica}

Luís Neves e Sandra Sousa, "O Estatuto Profissional e a Natureza da Figura do Agente de Execução », Configurações [Online], 20 | 2017, posto online no dia 28 dezembro 2017, consultado o 01 maio 2019. URL : http://journals.openedition.org/configuracoes/4238 ; DOI : 10.4000/configuracoes.4238 
Neves, Luís; Sousa, Sandra - 0 Estatuto Profissional e a Natureza da Figura do Agente de Execução. Configurações, vol. 20, 2017, pp. 109-124.

\section{O Estatuto Profissional e a Natureza da Figura do Agente de Execução}

LUÍS NEVES*

Solicitador

SANDRA SOUSA**

Sem filiação

Resumo

No que respeita a eficiência do processo executivo, o papel do Agente de Execução (AE) é fundamental na interação com os organismos e sistema público, percepcionando a justiça em ação. O estatuto profissional e a natureza da figura do AE explora-se enquanto o verdadeiro profissional liberal (independente, com autonomia técnica e tática) ou "funcionário público" ("autoridade pública", funções públicas supra-partes). Apesar da atividade de AE ser de natureza liberal, prossegue um notório e determinante interesse público provindo das instituições governamentais e deve ser detentora de uma função, dotada de uma atribuição legal para o exercício de poderes públicos de relevância social, e percecionada enquanto forma de intervenção judiciária e social.

Palavras-chave: Agente de Execução; Estatuto profissional; Autonomia técnica e tática; Intervenção social.

\footnotetext{
Abstract

The Professional Status and Nature of the Figure of the Executive Requester

With respect to the efficiency of the executive process, the role of the execution requester is fundamental in the interaction with the organisms and public system, perceiving justice in action. The professional status and nature of the ER figure is explored as a true liberal professional (independent, with technical and tactical autonomy) or "civil servant" ("public authority", public functions supra-parties). Although the ER's activity is liberal in nature, a notorious and decisive public interest proceeds from governmental institutions and it must be: holder of a function, endowed with a legal attribution for the exercise of public powers of social relevance, and perceived as a form of judicial and social intervention.

*E-mail: 4083@solicitador.net

**E-mail: sandrasmsousa75@gmail.com
} 
Keywords: Execution requester; Professional status; Technical and tactical autonomy; Social intervention.

\section{Résumé}

Le statut professionnel et la nature de la figure d'buissier de justice

En ce qui concerne l'efficacité de la procédure d'exécution, le rôle d'huissier de justice est essentiel dans l'interaction avec les organismes et le système public, afin de percevoir la justice en action. Le statut professionnel et la nature de la figure d'HJ est exploité en tant que le vrai professionnel libéral (indépendant, avec une autonomie technique et tactique) ou en tant qu'" agent public (" autorité publique», fonctions publiques supra-parties). Bien que l'activité d'HJ ait une nature libérale, celle-ci poursuit un intérêt public réel et déterminant provenant des institutions gouvernementales et doi être : titulaire d'une fonction, dotée d'une attribution légale pour l'exercice de pouvoirs publics ayant un volet social important, et perçue comme une forme d'intervention judiciaire et sociale.

Mots-clés: huissier de justice ; statut professionnel ; autonomie technique et tactique ; intervention sociale.

\section{Introdução}

Esta reflexão foi elaborada em 2015, ano em que se deu a transição da Câmara dos Solicitadores para a Ordem dos Solicitadores e Agentes de Execução (OSAE). Optou-se como tema a explorar o estatuto profissional e a natureza da figura do AE considerando a seguinte dicotomia: entre o verdadeiro profissional liberal (independente e com autonomia técnica e tática) ou "funcionário público" (ou "autoridade pública" - funções públicas supra-partes).

$\mathrm{Na}$ medida em que a discussão de qualquer que seja a profissão traz diferentes pontos de vista, tornou-se pertinente realizar uma análise e apreciação dos argumentos das várias teses em confronto, acompanhando para tal uma reflexão dos quatro momentos que a lei foi alterada no que concerne o estatuto da atual OSAE, e por outro lado explanar, dentro do direito do trabalho e da sociologia das profissões, os conceitos de profissional liberal, função pública e demais que lhes estejam associados ${ }^{1}$.

\section{Regime de Trabalho - Autonomia Técnica e Tática}

As competências do AE não se limitam às habituais de uma profissão liberal, englobando atos próprios de oficial público e para efeitos de responsabilidade

1 De forma a completar a análise efetuada considerou-se fundamental abordar a proposta de lei n. ${ }^{\circ} 308$ XII do Estatuto da Ordem dos Solicitadores e Agentes de Execução (EOSAE), e o Código Deontológico dos Solicitadores e Agentes de Execução (CDSAE). civil $^{2}$ surgem os aspetos de ordem privatística que resultam, designadamente, no grau de autonomia perante o juiz, na forma de designação, no regime de honorários, nas regras de substituição e de destituição, na obrigatoriedade de seguro ou no facto do recrutamento, nomeação, inspeção e ação disciplinar serem da competência de uma entidade que não integra a administração pública.

Numa ótica em que a análise da profissão é importante na medida em que o seu regime condiciona os resultados, verifica-se que o $\mathrm{AE}$, normalmente surge sem um vínculo laboral que pressuponha dependente de terceiros, sendo desta forma um profissional liberal independente, cujas competências específicas e funções que lhe são atribuídas podem ser exercidas nos termos do Estatuto da OSAE, e sob a fiscalização da Comissão para a Eficácia das Execuções.

Acrescenta-se o facto de apesar de ser uma atividade de natureza liberal, prossegue um notório e determinante interesse público. Neste sentido, deve ser detentora de uma função, dotada de uma atribuição legal para o exercício de poderes públicos de grande relevância social.

Mesmo partindo do princípio que o AE é um profissional liberal independente, sabe-se que as suas funções são públicas e deste modo é imprescindível perceber o significado de trabalho subordinado por um lado, e por outro de trabalho autónomo. Da mesma forma, outros conceitos, como contrato de trabalho, trabalho em funções públicas e profissional liberal devem ser escrutinados.

No trabalho subordinado o trabalhador, de livre vontade, transfere para terceiros a direção sobre o seu trabalho, sujeitando-se, ao poder de organização, de controlo e ao poder disciplinar destes, em troca de uma remuneração. Deste modo, o contrato de trabalho pode ser visto como objeto "da prestação de uma actividade e, como elemento típico e distintivo, a subordinação jurídica do trabalhador, traduzida no poder do empregador de conformar, através de ordens, directivas e instruções, a prestação a que o trabalhador se obrigou" (CEJ, 2014: 74).

Pode-se ainda considerar a definição que consta no artigo $11^{\circ}$ do Código do Trabalho sobre contrato de trabalho: "Contrato de trabalho é aquele pelo qual uma pessoa singular se obriga, mediante retribuição, a prestar a sua actividade a outra ou outras pessoas, no âmbito de organização e sob a autoridade destas.” (Portugal, 2012: 18).

Ao afirmar que o AE exerce funções públicas, é de todo importante perceber a lei no que concerne ao trabalho em funções públicas, nomeadamente os artigos $6^{\circ}$ e $7^{\circ}$ da Lei Geral do Trabalho em Funções Públicas, ou seja, em que consiste e na definição de contrato de trabalho ${ }^{3}$. De facto,

2 A responsabilidade civil que aos agentes de execução for imputada, no âmbito do exercício da sua atividade, obedece ao regime geral

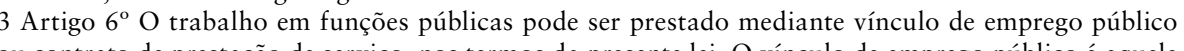
pelo qual uma pessoa singular presta a sua ativida presente lei. O vínculo de emprego público é aquele e mediante remuneração. $O$ vínculo de emprego público reveste as seguintes modalidades: contrato de trabalho em funções públicas; nomeação; comissão de serviço. O vínculo de emprego público pode ser 
as funções exercidas, e tarefas atribuídas são de caráter público, mas no que toca ao regime de trabalho não são aplicados os preceitos de um trabalhador em funções públicas propriamente dito, uma vez que o contrato de trabalho não existe nos moldes apresentados, e não existe um vínculo que subjugue o $\mathrm{AE}$ ao Estado, pelo menos, em termos de emprego público.

Este profissional reveste-se de uma autonomia técnica utilizando os expedientes legais ao seu dispor no enquadramento concreto do processo, e tática, fazendo a gestão geral do processo pouco igualável noutras profissões, com a exceção de algumas, como a dos notários e administradores judiciais.

Pode-se afirmar que se trata do verdadeiro profissional independente, e a sua autonomia teve um reforço a partir da reforma de 2003 a qual integrou a atividade do AE nos quadros gerais da responsabilidade civil extracontratual. Realça-se que apesar de aos agentes de execução terem sido atribuídos poderes que anteriormente eram exercidos por oficiais de justiça, sob direta subordinação ao juiz do processo até 2008 , e independência deste a partir de então, certos aspetos que decorrem do seu estatuto profissional, como o modo de designação ou do grau de autonomia que lhes é atribuído no âmbito da ação executiva requerem que pelo exercício da sua atividade respondam nos termos do direito privado.

Esta autonomia técnica e tática encontra-se no dever da independência, segundo Benjamim Rodrigues na sua análise ainda da proposta do CDSAE, relativamente ao artigo $27^{\circ}$, n. $^{\circ} 1$, atual $26^{\circ}$ n. ${ }^{\circ} 1$ do regulamento $202 / 2015$, cujo preceito refere que o $\mathrm{AE}$ "ainda que tenha sido nomeado pelo exequente, não é mandatário ou representante do mesmo, assim se pretendendo afirmar a sua autonomia e independência, estando "supra-partes"” (Rodrigues, 2015b: 40).

No trabalho autónomo, o trabalhador detém o poder de direção da própria atividade, ou seja, por conta própria tem o poder de organizar, controlar autonomamente e disciplinar as suas atividades, sem qualquer subordinação hierárquica. É o caso do profissional liberal, que no caso do AE se rege pelo regime geral e pelo ECS (Estatuto da Câmara dos Solicitadores), nomeadamente pelo artigo $116 .^{\circ}$ do exercício da atividade de AE: "As competências específicas de $\mathrm{AE}$ e as demais funções que lhe forem atribuídas podem ser exercidas nos termos deste Estatuto e da lei e sob fiscalização da Comissão para a Eficácia das Execuções (alteração introduzida pelo DecretoLei no 226/2008 de 20 de novembro)" (Câmara dos Solicitadores, 2008: 70).

Como definição de profissão, no âmbito da sociologia das profissões, realça-se a definição integrada por quatro perspetivas complementares, a partir dos estudos de Dubar, Tripier e Boussard (2015), pode ser comparada com a perspetiva abordada relativamente à autonomia técnica e tática do AE. Assim, profissão pode ser uma declaração, enquanto identidade profissional; uma especialização profissional; como um emprego, enquanto classificação profissional; e como função, enquanto uma posição profissional no seio de uma organização.

No âmbito das reformas da ação executiva levadas a cabo em 2003, 2008 e 2013, os Agentes de Execução foram reforçando a sua classe profissional, cuja configuração foi sendo integrada pelas alterações efetuadas ao EOSAE. Com alguma liberdade dado o funcionamento da atividade fora dos limites físicos das secretarias judiciais, foi sendo permitido aos agentes de execução que organizassem o seu trabalho com um nível de autonomia semelhante aos profissionais que exercem profissões liberais, acarretando com os custos e arrecadando os benefícios inerentes.

Pode-se afirmar, segundo alguns autores, que os agentes de execução estão submetidos a um estatuto híbrido, no qual surgem aspetos ligados à cooperação na Administração da Justiça cível, acabando por prevalecer a vertente liberal da sua atividade, a qual é revelada conforme o artigo $719^{\circ}$ do Código de Processo Civil (CPC), designadamente através do modo de recrutamento, da forma de designação (n. ${ }^{\circ}$ s 3 e 4), do grau de autonomia relativamente ao juiz (n. ${ }^{\circ} 1$ ), a par do grau de dependência em relação ao exequente (n. ${ }^{\circ}$ 6), da faculdade de delegar a execução de atos (artigo. $128^{\circ}$ do ECS). (cf. Acórdão de 11-04-2013).

No que concerne esta autonomia e na linha de Lopes do Rego, para quem o solicitador de execução é um "profissional liberal independente" (cit in Acórdão de 11-04-2013) é bem ténue o vínculo do solicitador de execução relativamente ao juiz do processo de execução, cujo controlo executivo traduz-se de uma forma genérica permitindo o exercício da atividade com uma autonomia muito própria de um profissional liberal.

Se esta classe profissional se sujeitasse ao regime do Estado, como outras entidades públicas, seria exigido um nível de intervenção externa e o aumento do grau de controlo sobre as suas atividades, o que conduziria a uma descaracterização estatutária tão arduamente defendida ao longo das diferentes reformas da ação executiva, e mesmo recentemente com a proposta de Lei para o EOSAE assim como com a publicação do regulamento do CDSAE, e finalmente com a Lei 154/2015.

Os deveres estatutários em conformidade com os princípios da independência e da integridade são partes fundamentais da lei mais recente, no que concerne o estatuto profissional do $\mathrm{AE}$, ou seja, surgem "dois inovadores princípios deontológicos" (Rodrigues, 2015c: 49).

Deste modo, por um lado, com a Proposta de Lei n. ${ }^{\circ}$ 308/XII do EOSAE os princípios da independência e da integridade são consagrados em conjunto ${ }^{4}$. Por outro lado, e já em Diário da República, no CDSAE, esses dois princípios são consagrados separadamente no artigo 2 e $3^{\circ}$, respetivamente

$4 \mathrm{O}$ solicitador $\mathrm{e} \mathrm{o}$ agente de execução são indispensáveis à realização de tarefas de interesse público e à administração da justiça e, como tal, devem ter um comportamento público e profissional adequado mente os seus deveres. (Presidência do Conselho de Ministros, 2015: 11). 
a integridade e a independência, atribuindo assim uma importância acrescida a cada um deles e realçando a responsabilidade e o interesse público desses princípios no que concerne as competências do Solicitador e $\mathrm{AE}^{5}$. Segundo Benjamim Rodrigues o princípio da integridade à luz da proposta do ESOAE, surge "como uma postura de "não corruptibilidade" por valores espúrios ou tidos por não corretos ou louváveis numa sociedade de direito e democrática". No que concerne o princípio da independência o autor constata que nessa proposta "o legislador entendeu que o solicitador e o agente de execução, no exercício da sua profissão ou funções, mantêm sempre, em quaisquer circunstâncias, a sua independência” (2015c: 50).

\section{Agente de Execução - Funções Públicas Supra-Partes}

Conforme a proposta de lei n. ${ }^{\circ}$ 308/XII do EOSAE, "a nacionalidade portuguesa constitui requisito de inscrição no colégio dos agentes de execução atendendo ao facto de este profissional estar investido de relevantes poderes de autoridade pública (ius imperii) que o Estado nele delega para que se assegure o cumprimento, por via coerciva, de obrigações não cumpridas atempada e de forma voluntária pelos devedores" (Presidência do Conselho de Ministros, 2015: 10). Sublinha-se neste extrato que faz parte da exposição de motivos ao EOSAE, a afirmação da existência de poderes de autoridade pública delegados naquele profissional pelo Estado.

A questão da responsabilidade civil (artigo $123^{\circ}$ do EOSAE) e da submissão do AE no que concerne a mesma deve ser vista considerando o caráter das suas funções públicas "acima das partes" ou "supra-partes", isto é, para além dos diferentes intervenientes no processo executivo. Conforme é observado por Virgínio Ribeiro em dois momentos da reforma da ação executiva, "na prática, a Reforma de 2003, transformou um profissional liberal num funcionário público, remunerado pelas partes" e ainda verifica que a partir do regime de 2008, que a atividade do AE se orienta principalmente pelas regras do "contrato de prestação de serviços de direito privado, ainda que na respectiva execução devam ser observadas maioritariamente regras de natureza pública" assim como acontece com os notários (Ribeiro cit. in Acórdão 11-04-2013).

O AE deve estar "supra-partes" no âmbito da sua atuação enquanto pivô do processo executivo. Instintivamente este pode ser confrontado com uma situação problemática de cumprir a lei ou agir em sintonia com os desejos pretendidos do exequente: se por um lado, cumprir o que se encontra tipificado na legislação corre o risco de ser substituído livremente pelo exequente, por outro lado se agir em conformidade com o que este pretende corre o risco de ser alvo de um processo disciplinar, por parte das entidades competentes para o efeito.

Quando Benjamim Rodrigues sublinha que a interiorização da dimensão deontológica da independência supra-partes demorará a ter lugar, verifica-se que, com a publicação do regulamento do CDSAE a 28 de abril de 2015 , dá-se mais um passo para que, conforme o autor "a afirmação da natureza de profissional liberal do agente de execução, [se concretize], ainda que mesclado de "entidade pública" e supra-partes" (Rodrigues, 2015b: 40).

Tendo em conta o EOSAE poder-se-ia sublinhar no que concerne as funções públicas exercidas pelo AE que este "é o auxiliar da justiça que, na prossecução do interesse público, exerce poderes de autoridade pública no cumprimento das diligências que realiza nos processos de execução nas notificações, nas citações, nas apreensões, nas vendas e nas publicações no âmbito de processos judiciais...”. E ainda no que respeita a cumulação de funções o mesmo documento enuncia que "importa evidenciar o preceito estatutário que consagra a incompatibilidade do exercício das funções de AE com o exercício do mandato judicial, assim como com o exercício da atividade de administrador judicial.” (Presidência do Conselho de Ministros, 2015: 15).

$\mathrm{Na}$ realidade, na tramitação processual da ação executiva, o AE cumpre com poderes inquestionáveis de autoridade pública, confrontando-se com deveres estatutários gerais e especiais, de imparcialidade e de legalidade, e a estreitas regras de incompatibilidades e impedimentos em conformidade com o exercício de funções públicas, inerentes à administração da justiça em que intervém e promove factos ocorridos dessa atuação. Ainda sobre as funções públicas por parte de um trabalhador liberal como é o AE, Teixeira de Sousa, verifica que:

.o solicitador, apesar de ser uma entidade privada, exerce funções públicas, pelo que se está perante um dos casos de exercício privado de fun çôes públicas e num trabalho sobre o novo regime de 2008, afirma que o çoes publicas e num trabalho sobre o novo regime de 2008, afirma que o
agente de execução responde ao abrigo do Regime da Responsabilidade agente de execução responde ao abrigo do Regime da Responsabilidade
Civil Extracontratual do Estado, sendo o Estado exclusivamente responsável pelos danos que resultem de ações ou omissões ilícitas, cometidas com culpa leve, pelo agente de execução (cit. por Acórdão 11-04-2013).

Uma vez que se trata dum elemento recentemente aprovado, o CDSAE não pode deixar de ser referenciado quando se sublinha a importância da autoridade e funções públicas no estatuto do AE, conforme artigo $23^{\circ}$ no "exercício da atividade de agente de execução e prática de atos processuais (...) visando a prossecução do interesse público e cabendo-lhe o exercício de poderes de autoridade pública, o AE deve atuar sempre com o devido rigor e ponderação”. 


\section{Agente de Execução - Perspetivas em Confronto}

Não se pode ignorar que a classe profissional dos agentes de execução levanta diferentes posições e coloca as mesmas em confronto, seja no que diz respeito à sua definição, às suas competências, à relação que estabelecem com as partes (juiz, executante, executado, secretaria e outros) ou mesmo ao vínculo que estabelece em termos de responsabilidade civil.

Segundo a OSAE e de forma a transmitir plenamente as diferentes competências do AE, define este profissional como um profissional liberal que exerce funções públicas, encontrando-se estatutariamente sujeito a um regime específico, nomeadamente, em matéria de acesso à profissão e respetiva formação, incompatibilidades e impedimentos, direitos e deveres, remuneração dos seus serviços, controlo e disciplina. O AE não atua como mandatário das partes e está sujeito a um tarifário pelos honorários. Tramita todo o processo executivo, procedendo a citações em processos declarativos (quando frustradas por via postal) (cf. site OSAE).

Outras perspetivas são de realçar, que permitem uma confrontação de posições. Na perspetiva de Maria João Areias o AE “é um órgão da execução, a par do juiz de execução, exercendo o poder executivo do Estado - no desempenho da sua função para-jurisdicional, exerce prorrogativas de poder público -, isto sem prejuízo de os seus atos e decisões poderem ser impugnados pelo juiz de execução.” (Areias, 2013: 8).

Já Carlos Lopes Rego considera que "esta figura [do AE] se reveste de um "caráter híbrido e heterogéneo" que acaba por compreender duas figuras totalmente diferentes: o Solicitador de Execução e o Oficial de Justiça" (cit. por Aquino, 2004: 4). Nesta linha de pensamento se for considerado o que está previsto no CPC, nos artigos $719^{\circ}$ e $720^{\circ}$, de facto o oficial de justiça pode exercer as funções de AE em determinadas situações e em algumas diligências. Outro autor que comunga desta posição de estatuto híbrido é Fernando Amâncio Ferreira para o qual "o encargo do solicitador de execução "apresenta-se com uma natureza híbrida, por reunir em si características próprias de um mandatário do credor e de um oficial de justiça" (cit. por Aquino, 2004: 4).

Acerca deste estatuto híbrido Maria João Areias refere que, mediante a "organização da sua atividade com a autonomia de quem exerce uma profissão liberal, escolhido pelo exequente e por este substituído, em simultâneo com o exercício de funções públicas, sujeito a deveres de independência, imparcialidade e legalidade - tem originado divergências quanto à sua submissão ao regime da responsabilidade civil extracontratual do Estado ou ao regime geral da responsabilidade civil” (2013: 9).

Quando a Comissão para o Acompanhamento dos Auxiliares de Justiça, é criada "é confiado o acompanhamento, fiscalização e disciplina dos auxiliares de justiça (entre os quais se incluem os agentes de execução), ao sujeitar a atividade dos seus órgãos à jurisdição administrativa, prevendo a possibilidade de recurso para os tribunais administrativos das sanções disciplinares e contraordenações aplicadas por tal comissão" (Areias, 2013: 9). Isto poderia ser um fator deveras importante para equiparar os agentes de educação a outros agentes, no que concerne à subordinação do regime da responsabilidade civil prevista para aqueles que servem o Estado.

Segundo Leonardo Gomes Aquino o AE "é um profissional liberal independente sujeito a um triplo controle (Juiz, Câmara de Solicitadores e Legislativo - impedimentos e incompatibilidades) ...” (Aquino, 2004: 4). Este controlo, entretanto, foi diminuindo, dadas as mudanças introduzidas com a reforma da ação executiva de 2008 através do Decreto-Lei no 226/2008 de 20 de novembro e que tornou o controlo do processo judicial por parte do juiz muito mais reduzido dada a autonomia atribuída às competências do $\mathrm{AE}$.

Considerando a definição da atividade e exercício de $\mathrm{AE}$ na Lei n. ${ }^{\circ}$ 154/2015 no artigo $162^{\circ}$, nomeadamente que o AE é o auxiliar da justiça que, na prossecução do interesse público, exerce poderes de autoridade pública, verifica-se que existe mais uma vez uma intenção de reforço do poder de autoridade pública do AE. Não se pode deixar também de constatar que têm sido atribuídos poderes que influenciam terceiros, como do executado, inicialmente com o controlo geral do juiz e atualmente, segundo o $\mathrm{n}^{\circ} 1$ do artigo $723^{\circ}$ do CPC, o controlo judicial efetua-se por meio de iniciativa externa.

Outros autores, como Alves de Brito, observam o AE na sua relação com o exequente no que concerne a qualificação do vínculo, designadamente para o fortalecimento do mesmo, constatando que existem "verdadeiros poderes de autoridade", parecendo "ser possível a hipótese de um novo auxiliar da justiça", observando ainda que "a responsabilização do agente de execução pode constituir o Estado numa obrigação de indemnizar” (cit. por Acórdão11-04-2013).

Relativamente à responsabilidade do $\mathrm{AE}$ e o poder jurisdicional que lhe foi sendo atribuído ao longo dos últimos anos, nas diferentes reformas da ação executiva, Lebre de Freitas conclui que, "havendo responsabilidade do solicitador perante as partes ou terceiro, o Estado pode, por sua vez, responder nos termos gerais da responsabilidade do Estado por actos dos seus agentes", assim como "não impede a responsabilidade do Estado pelos actos ilícitos que o solicitador de execução pratique no exercício da função, nos termos gerais da responsabilidade do Estado pelos actos dos seus funcionários e agentes” (cit. por Acórdão 11-04-2013).

Numa análise sociológica comparativa da noção de profissão, depara-se com diferentes problemáticas teóricas, que não apraz aqui desenvolver, mas que são importantes na definição de profissão completando as definições de trabalhador independente, ou profissional liberal. São exemplos dessas problemáticas teóricas, os trabalhos dos autores Dubar, Tripier e Boussard (2015), os quais contestam as teorias funcionalistas (baseadas nas profissões tradicionais, nomeadamente médico e advogado), e as quais ocuparam 
um espaço de reflexão para questões sobre os grupos profissionais, em particular, novas profissões, novas conceptualizações, onde o AE se encaixa.

Para os autores portugueses, e segundo Rodrigues (2002), a perspetiva estática é substituída por uma perspetiva dinâmica da profissionalização enquanto processo. As novas formas de organização profissional, ou os novos grupos profissionais, como é o caso do AE, encaixam nesta linha de análise dinâmica. Conforme Santos (2015), aquando a reforma do processo executivo, a ausência de preparação e adaptação à nova realidade por parte das várias profissões forenses e a ausência (inicial) de formação da figura do AE, permitiram que os obstáculos desse processo passassem para um plano de prioridades diferente, contemplado pelas competências do AE, que serão exploradas mais à frente nesta reflexão.

Outra perspetiva a destacar é de Larson (1977), para a qual a noção de profissão usada pelos funcionalistas é uma ferramenta incapaz de conceptualmente capturar as dinâmicas das profissões nas sociedades capitalistas contemporâneas, onde se situam os ditos grupos profissionais. Já para Freidson (2001), a noção de profissão identifica-se com um princípio ocupacional de organização do trabalho, e pode-se ver como uma construção histórica localizada em contextos sociais particulares. Para este autor a erosão progressiva da autonomia profissional face ao desenvolvimento do capitalismo aparece como uma das conclusões mais importantes no que concerne as novas formas do trabalho profissional.

\section{Agente de Execução - Incompatibilidades e Impedimentos}

Refletindo no papel que a profissão de AE desempenha na administração da justiça de Portugal, entre as diferentes profissões forenses, e tomando como princípios basilares o ECS que a rege e a Lei, com a devida e adequada referência às suas incompatibilidades e impedimentos abaixo explorada, torna-se conveniente mais uma vez citar a exposição de motivos contida na Proposta de Lei ${ }^{\circ}$ 308/XII do EOSAE, designadamente a intenção deste diploma pretender "conformar a disciplina jurídica atinente a estes profissionais da área do direito com o regime de criação, organização e funcionamento das associações públicas profissionais, aprovado pela Lei n..$^{\circ}$ 2/2013, de 10 de janeiro, e aproveitando-se o ensejo para dignificar o seu estatuto profissional, considerando o papel fundamental que desempenham na administração da justiça no nosso país." (Presidência do Conselho de Ministros, 2015:1). De facto a Lei referida, é por si só uma inovação no que se relaciona com o acesso e exercício da profissão conforme o artigo $27^{\circ}, \mathrm{n}^{\circ} 1$ "que veio permitir que possam ser constituídas sociedades de profissionais que tenham por objecto principal o exercício de profissões organizadas numa única associação pública profissional, em conjunto ou em separado com o exercício de outras profissões ou actividades” (Rodrigues: 2015a: 51).
$\mathrm{Na}$ análise que se segue, a linha de orientação consiste em analisar os artigos que consideram as funções do $\mathrm{AE}$ com ligação e/ou vínculo ao funcionalismo público, explorando os artigos contidos no ECS e na Proposta de Lei da EOSAE no que concerne as incompatibilidades e impedimentos da atividade e exercício da profissão do AE. A perspetiva adotada da profissionalização do AE é dinâmica, e a análise tem de ser visualizada enquanto um processo evolutivo. No artigo $114^{\circ}$ do ECS estão espelhadas as incompatibilidades genéricas, das quais e no que o exercício da solicitadoria diz respeito se destacam as seguintes funções:

Titular ou membro de órgão de soberania, com exceção da Assemblei da República, assessor, membro e funcionário ou agente contratado do órgão ou respectivos gabinetes; titular ou membro do Governo Regional e assessor, funcionário ou agente contratado dos respectivos gabinetes; provedor de justiça, adjunto, assessor, funcionário ou agente contratado do serviço; funcionário de quaisquer serviços públicos de natureza central, regional ou local, ainda que personalizados, com exceção dos docentes de qualquer disciplina e em qualquer estabelecimento de ensino; gestor público, nos termos do respetivo Estatuto (Câmara dos Solicitadores, 2008: 68).

No Artigo 102. (incompatibilidades genéricas) da proposta de lei no 308/ XII destacam-se as seguintes funções e atividades, mais uma numa ótica de vínculo à função pública: membro do Tribunal Constitucional e respetivos adjuntos, trabalhadores com vínculo de emprego público ou contratados; membro do Tribunal de Contas e os respetivos adjuntos, trabalhadores com vínculo de emprego público ou contratados; provedor de justiça e os respetivos adjuntos, trabalhadores com vínculo de emprego público ou contratados do respetivo serviço; magistrado, ainda que não integrado em órgão ou função jurisdicional; assessor, administrador, trabalhador com vínculo de emprego público ou contratado de qualquer tribunal; gestor público; trabalhador com vínculo de emprego público ou contratado de quaisquer serviços ou entidades que possuam natureza pública ou prossigam finalidades de interesse público, de natureza central, regional ou local (cf. Presidência do Conselho de Ministros, 2015: 95).

No que concernem as incompatibilidades específicas do AE, cumpre a tarefa de uma análise comparada entre o que estava legislado no ECS, e o que surge no EOSAE, conforme o quadro 
Quadro 1: Incompatibilidades do AE

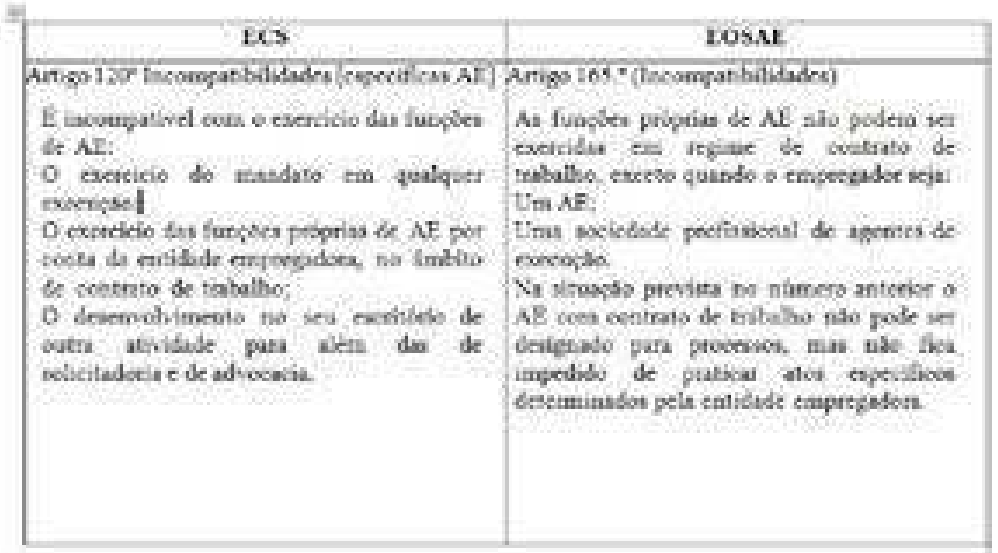

O quadro acima permite uma melhor clarificação da ideia de que há uma intenção de especificidade maior na proposta de lei para o EOSAE, dada mais uma vez a abordagem do estatuto profissional do AE, tendo em conta a sua autonomia técnica e tática por um lado, e por outro, a autoridade que lhe é atribuída em termos públicos.

Relativamente aos impedimentos, também devem ser considerados os genéricos e os específicos ao AE plasmados tanto no ECS como no EOSAE. $\mathrm{Na}$ mesma linha de análise, e como relevante para esta reflexão, destaca-se no artigo $115^{\circ}$ que os agentes de execução estão impedidos de exercer o mandato judicial: os funcionários ou agentes administrativos, na situação de aposentados, de inatividade, de licença ilimitada ou de reserva, em quaisquer assuntos em que estejam em causa os serviços públicos ou administrativos a que estiveram ligados, durante um período de três anos a contar da data em que tenham passado a estar numa daquelas referidas situações.

Já no EOSAE, no artigo $103^{\circ}$ sublinha-se o seguinte: praticar atos profissionais e mover qualquer influência junto de entidades, públicas ou privadas, onde desempenhe ou tenha desempenhado funções cujo exercício possa suscitar, em concreto, uma incompatibilidade, se aqueles atos ou influências entrarem em conflito com as regras deontológicas contidas no presente Estatuto, e ainda que os associados que sejam membros das assembleias representativas das autarquias locais, bem como os respetivos adjuntos, assessores, secretários, trabalhadores com vínculo de emprego público ou outros contratados dos respetivos gabinetes ou serviços, estão impedidos, em qualquer foro, de patrocinar, diretamente ou por intermédio de sociedade de que sejam sócios, ações contra as respetivas autarquias locais, bem como de intervir em qualquer atividade da assembleia a que pertençam sobre assuntos em que tenham interesse profissional diretamente ou por intermédio de sociedade a que pertençam.

Quanto aos impedimentos e suspeições do AE, cumpre mais uma vez analisar de forma comparada o que está previsto nos dois documentos através do quadro 2:

Quadro 2: Impedimentos do AE

\begin{tabular}{|c|c|}
\hline $\mathrm{BCS}$ & bosal: \\
\hline 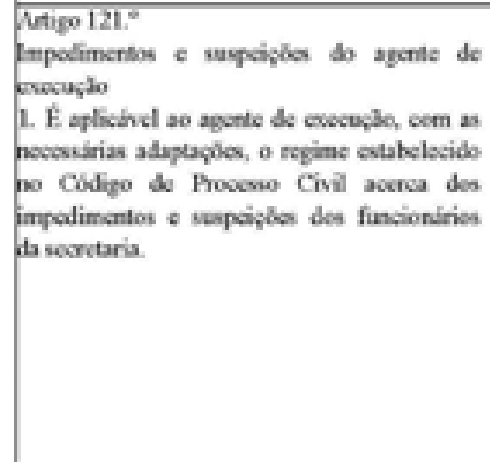 & 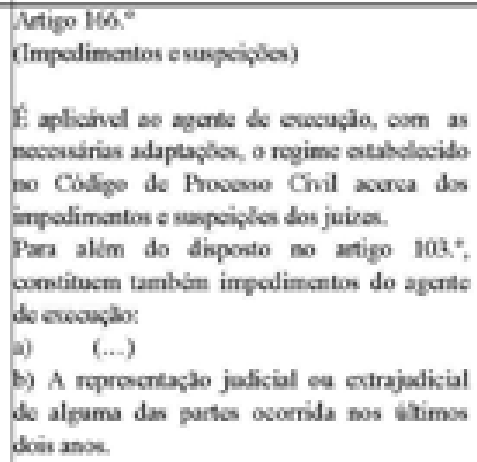 \\
\hline
\end{tabular}

Verifica-se que na proposta de lei do ESOAE há um alargamento no âmbito dos impedimentos, relativamente ao ECS, o que se encontra em sintonia por oposição com o aumento da autonomia atribuída ao AE nas últimas reformas da ação executiva.

\section{Conclusão}

O processo executivo veio transpor, perante uma maior necessidade de eficácia nas execuções a atual figura do AE, entendendo-se o mesmo enquanto pivô da ação executiva que exerce a sua profissão, dotado de autoridade pública estando vinculado a uma ação de independência e de imparcialidade que cabe a realização de todos os atos da ação executiva, devendo estar "supra-partes" no âmbito da sua atuação. Deste modo, a atividade do AE, enquanto forma de intervenção judiciária, deve ser percepcionada como uma metodologia que envolve diferentes níveis de conhecimento ao nível do saber-saber, saber fazer e saber estar.

É de notar que também nos dias de hoje não se pode ignorar que o processo executivo apenas vê cumprido o seu papel de pacificação social, na medida em que vai de encontro também à opinião pública, no sentido de a convencer da conformidade da decisão ou ação efetuada ou executada. 
Só produz efeito o processo que permite compreender e resolver o conflito entre a regra de direito e o livre arbítrio dos homens. Mediante esta finalidade, a atuação dos agentes de execução, apesar da sua autonomia técnica e tática, deve ser vertida segundo as exigências da época histórica no âmbito cultural, sociológico e tecnológico do tempo processual e da sua própria concepção axiológica. Cada ação deverá traduzir um constante compromisso de equidade.

No âmbito da atual reforma executiva, em que o juiz não aparece no controlo geral do processo, seria de extrema importância a aplicabilidade de um estatuto consistente voltado para a autonomia do AE, sendo que resultante de tal facto, estabelecia-se a existência de um controlo disciplinar mais apertado e a livre ação de reclamação dos atos e a impugnação de decisões daquele perante o juiz, quer para o executado, quer para o exequente, não descartando a hipótese, de haver cumulativamente a esta situação uma distribuição feita unicamente pelo tribunal, nos moldes atualmente atribuídos, ao PEPEX (Procedimento Extrajudicial Pré-Executivo), atenuando assim de certa forma a proximidade proeminente entre exequente e AE.

O Estado, cada vez mais, atribui as suas competências públicas, enquanto regulador da ordem e regras sociais, a profissionais liberais, escapulindo-se assim de certa forma a uma responsabilidade civil e com obtenção de uma rentabilidade em termos de custos para a máquina do estado, no que toca à admissão de agentes administrativos. Canaliza essa mesma responsabilidade para o direito privatístico e para uma realidade dissimulada de um aparente vínculo laboral seguro, como acontece com tantos profissionais liberais na situação de "falsos recibos verdes"

O EOSAE vem sinalizar uma série de situações indiciadas no exercício da atividade profissional do AE, salvaguardando a mesma e alargando o âmbito da sua regulamentação, permitindo uma orientação mais próxima de uma realidade social onde este profissional tem um papel preponderante de resolução jurídica e jurisdicional e consequentemente de pacificação social, e onde o seu grupo profissional se ajusta à realidade tradicional das profissões forenses.

\section{Bibliografia}

AMARAL, J. A. Pais de (2013), Direito Processual Civil, Coimbra, Edições Almedina. AMORIM, João Pacheco de (sem data), A Liberdade de Profissão, disponível em <http://repositorio-aberto.up.pt/bitstream/10216/23954/2/2761.pdf> [Consultado em: 25-05-2015].

AQUINO, Leonardo Gomes de (2008), O AE - um contributo para a efectividade do processo executivo português - breves considerações, disponível em <http://www.verbojuridico. com/doutrina/civil/civel_09\%20-\%20eliminar.html> [Consultado em: 25-05-2015].
AREIAS, Maria João (2012), A livre substituição do AE por parte do exequente e o direito constitucionalmente consagrado a um processo equitativo - o Acórdão do Tribunal Constitucional n. ${ }^{\circ}$ 199/2012, de 24 de Abril de 2012, disponível em <http://julgar. pt/wp-content/uploads/2014/05/A_livre_substitui\%C3\%A7\%C3\%A3o_do_agente_ de_execu\%C3\%A7\%C3\%A3o_por_parte_do_exeque nte.pdf> [Consultado em: 03-06-2015].

AREIAS, Maria João (2013), A substituição do AE por parte do exequente e a sua conformidade com o direito constitucionalmente consagrado a um processo equitativo, Porto, disponível em <http://www.abzp.pt/docs/apresentaodra.mariajooareias/espinho-29-11-2013-dra-maria-joao-areias--a-livre-substituicao.pdf> [Consultado em: 04-06-2015].

CÂMARA DOS SOLICITADORES (2008), Estatuto com as alterações introduzidas pelo ÂMARA DOS SOLICITADORES (2008), Estatuto com as alterações intro
Decreto-Lei n.․ 226/2008 de 20 de Novembro, Diploma consolidado: JCM.

CÂMARA DOS SOLICITADORES, Colégio de Especialidade de Agentes de Execução (2013), Código de Processo Civil, versão 2 agosto de 2013. Disponível em <http://solicitador.net/ uploads/cms_page_media/2013/8/13/Novo\%20CPC\%20-\%20publicado\%20v2.pdf> [Consultado em: 04-06-2015].

CENTRO DE ESTUDOS JUDICIÁRIOS (2013), Trabalho subordinado e trabalho autónomo: presunção legal e método indiciário, Série Formação Inicial, Lisboa, CEJ disponível em <http://www.cej.mj.pt/cej/recursos/ebooks/trabalho/trabalhosubordinado_trabalho autonomo.pdf?id=9\&username=guest $>$ [Consultado em: 15-05-2015].

DIÁRIO DA REPÚBLICA (2003), Decreto-Lei no 38/2003 de 3 de agosto - Diário da República, $1^{a}$ Série A, n. ${ }^{\circ} 58$, de 3 de agosto.

DIÁRIO DA REPÚBLICA (2008), Decreto-Lei n. ${ }^{\circ} 226 / 2008$ de 20 de novembro, Diário da República, $1^{\text {a }}$ Série, de 20 de novembro.

DIÁRIO DA REPÚBLICA (2013), Lei n. ${ }^{\circ}$ 2/2013 de 10 de janeiro, Diário da República, $1^{a}$ Série, n. ${ }^{\circ} 7$, de 10 de janeiro.

DIÁRIO DA REPÚBLICA (2014). Lei n. ${ }^{\circ}$ 35/2014 de 20 de junho, Diário da República, $1^{a}$ Série, n. ${ }^{\circ} 117$, de 20 de junho.

DIÁRIO DA REPÚBLICA (2015), Regulamento n. 202/2015 de 28 de abril, Diário da República, $2^{a}$ Série, n. ${ }^{\circ} 82$, de 28 de abril.

DIÁRIO DA REPÚBLICA (2015), Lei n. ${ }^{\circ}$ 154/2015 de 14 de setembro, Diário da República, $1^{a}$ Série, n. ${ }^{\circ} 179$, de 14 de setembro.

DUBAR, Claude; TRIPIER, Pierre; BOUSSARD, Valérie (2015), Sociologie des professions, Paris, Armand Colin

FREIDSON, Eliot (2001), Professionalism, the Third Logic, Cambridge, Polity Press. JURISPRUDÊNCIA DO SUPREMO TRIBUNAL DE JUSTIÇA (2013), Acórdão processo n. ${ }^{\circ} 5548 / 09.9$ TVLSNB.L1.S1, de 11 de abril de 2013, disponível em <http://www. dgsi.pt/jstj.nsf/954f0ce6ad9dd8b980256b5f003fa814/40d1dd1cca4b2c3580257b4b00 2fd3ab?OpenDocument\&Highlight=0,5548\%2F09.9TVLSNB.L1.S1> [Consultado em 10-07-2015].

LARSON, Magali (1977), The Rise of Professionalism: A Sociological Analysis, London, University of California Press Lta.PRESIDÊNCIA DO CONSELHO DE MINISTROS (2015), Proposta de Lei no 308/XII, disponível em <http://solicitador.net/uploads/cms _ page_media/2015/3/19/ppl308-XII.pdf $>$ [Consultado em: 20-04-2015]

PORTUGAL (2002), Código Civil Português, aprovado pelo decreto-lei n. 47344 de 25 de novembro de 1996, Coimbra, Livraria Almedina.

PORTUGAL (2012), Código do Trabalho, Aprovado pela Lei n. ${ }^{0} 7 / 2009$, de 12 de Fevereiro, Priberam Informática, S.A.. 
RODRIGUES, Benjamim Silva (2015a), Ventos de Mudança na Vida Profissional dos Solicitadores e Agentes de Execução: uma nova (des)ordem, ética e deontologia profissional (?). Tomo I, Lisboa, Rei dos Livros.

RODRIGUES, Benjamim Silva (2015b), Ventos de Mudança na Vida Profissional dos Solicitadores e Agentes de Execução: uma nova (des)ordem, ética e deontologia profissional (?). Tomo II, Lisboa, Rei dos Livros.

RODRIGUES, Benjamim Silva (2015c), Ventos de Mudança na Vida Profissional dos Solicitadores e Agentes de Execução: uma nova (des)ordem, ética e deontologia profissional (?). Tomo III, Lisboa, Rei dos Livros.

RODRIGUES, Maria de Lurdes (2002), Sociologia das Profissões, Oeiras, Celta Editora.

SANTOS, Boaventura de Sousa (dir.) (2007), A Acção Executiva em Avaliação: Uma Proposta de Reforma, Observatório Permanente da Justiça Portuguesa, Centro e Estudos Sociais, Faculdade de Economia Universidade de Coimbra.

SANTOS, Boaventura de Sousa (2015), Para uma revolução democrática da justiça, Coimbra, Almedina. 